\title{
Medical students' perceptions of video-linked lectures and video-streaming
}

\author{
RuoLan Wang ${ }^{\mathrm{a}}$, Karen Mattick ${ }^{\mathrm{b} *}$ and Elisabeth Dunne ${ }^{\mathrm{c}}$ \\ ${ }^{a}$ School of Education, University of Nottingham, UK; ${ }^{b}$ Institute of Clinical Education, \\ Peninsula College of Medicine \& Dentistry, Exeter, UK; ${ }^{c}$ Education Enhancement, University \\ of Exeter, UK
}

(Received 27 September 2009; final version received 3 December 2009)

\begin{abstract}
Video-linked lectures allow healthcare students across multiple sites, and between university and hospital bases, to come together for the purposes of shared teaching. Recording and streaming video-linked lectures allows students to view them at a later date and provides an additional resource to support student learning. As part of a UK Higher Education Academy-funded Pathfinder project, this study explored medical students' perceptions of video-linked lectures and video-streaming, and their impact on learning. The methodology involved semi-structured interviews with 20 undergraduate medical students across four sites and five year groups. Several key themes emerged from the analysis. Students generally preferred live lectures at the home site and saw interaction between sites as a major challenge. Students reported that their attendance at live lectures was not affected by the availability of streamed lectures and tended to be influenced more by the topic and speaker than the technical arrangements. These findings will inform other educators interested in employing similar video technologies in their teaching.
\end{abstract}

Keywords: video-linked lecture; video-streaming; student perceptions; decisionmaking; cross-campus teaching

\section{Introduction}

The rapid development in digital technologies such as video-conferencing and videostreaming adds a new dimension to education. Video-conferencing enables simultaneous (synchronous) communication between two or more sites (Raffelini 2006). It was initially used in business and industry in the early 1990s for meetings, but videolinked lectures were only occasionally used within higher education institutions (Carter et al. 1996). Since that time, it has proved to be a useful technology on merger between geographically distant audiences, with concomitant savings of time and resource. Video-streaming involves the conversion and compression of raw video files, thus enabling large files to be opened and viewed quickly (McCrohon et al. 2001). Recording and streaming live lectures and making them available as a reusable resource provides additional flexibility in learning. Students can search for particular information and reinforce their previous learning anytime and anywhere.

As well as recognising the significant potential of these technologies within higher education, a number of authors have highlighted some concerns. In the case of

*Corresponding author. Email: karen.mattick@pms.ac.uk 
video-conferencing, these have related to learning issues such as ensuring interaction and equality of learning experience between sites (Carville and Mitchell 2000; Knipe and Lee 2002), teaching issues such as staff development requirements (Freeman 1998) and organisational issues such as timetable coordination (Pitcher, Davidson, and Goldfinch 2000). In the case of video-streaming, the concerns have related to teaching issues regarding the impact on attendance of live events (for example, Bell et al. 2001; Moridani 2007) and technical issues such as Internet connection speed (McCrohon et al. 2001).

Despite the potential concerns, the following broad conclusions can be drawn from the literature with regard to populations of undergraduate healthcare students:

1) there appears to be no significant difference in academic performance following video-linked lectures when compared with face-to-face lectures (Soloman et al. 2004; Stain et al. 2005);

2) video-linked lectures seem to be an acceptable alternative to face-to-face delivery (Callas et al. 2004; Whitten et al. 2005; Mattick, Crocker, and Bligh 2007); and

3) fears that making educational materials available online will have a negative impact on student attendance at live events are probably unfounded (BillingsGagliardi and Mazor 2007; Mattick, Crocker, and Bligh 2007).

More detailed research is still very much needed to inform this rapidly developing field. A particular need for qualitative studies focusing on healthcare student perceptions of video-linked lectures and how decisions about lecture attendance are made has been identified (Billings-Gagliardi and Mazor 2007; Mattick, Crocker, and Bligh 2007). These authors have made an initial contribution to the field but detailed qualitative methodologies, such as focused semi-structured interview techniques, have still not been applied to the topic in order to gain better insights into the learner experience. In addition, the decision-making processes underpinning when and why students access video-streamed lectures, and how this is incorporated within individual student learning, are largely unexplored.

\section{Methodology}

\section{Aim}

The aim of this study was to build on what is known by investigating medical students' perceptions of video-linked lectures and video-streaming, and to explore how these technologies are used by individual students. It forms part of a larger study funded by the Joint Information Systems Committee in conjunction with the Higher Education Academy as part of the national Pathfinder initiative. ${ }^{1}$ The overall aim of the larger study (the Exeter Pathfinder project) was to further an understanding of the current role that video and conferencing technologies play in undergraduate student learning and their future potential.

\section{Context of the study}

The setting for the study was a medical school that comprises five main sites for curriculum provision across South West England. In this geographically distributed environment, staff and student communication is facilitated in lectures by using 
video-conferencing technology. The video-linked lectures allow students across multiple sites, and between university and hospital bases, to come together for the purposes of shared teaching. Many of the people giving lectures are healthcare professionals who can bring a diverse wealth of expertise and experience to the teaching context without having to travel between campuses. Their video-linked lectures are recorded and made available for access in a video-streamed format through the medical school's web-based managed learning environment as an additional resource to support student learning. Students are not obliged by the medical school to attend the lectures, although they are expected to cover the learning objectives in some other way if they choose not to attend the lectures.

\section{Sample}

A purposive sample of medical students $(n=20)$ were the participants in this research. The sample targeted a broad distribution of students across geographical location and year group. Within these groups, students were selected from the class lists at random. Invitation to participate in the study was via an email from one of the authors (K.M.). In total 64 invitations were sent, and the first 20 students to respond to the email were interviewed. The email invitation emphasised the purpose of the study, the voluntary nature of the interviews, and the desire to interview students who chose not to attend lectures or view streamed lectures as well as those who did.

\section{Interviews}

Semi-structured interviews were performed by one of the authors (R.L.W.) at a time and location to suit the participant. The medical school Research Ethics Committee gave full approval for the study and approved the question schedule (Appendix 1). Interviews were audio-recorded and transcribed verbatim. Thematic analysis was used to identify the key concepts that emerged from the data.

\section{Results}

The findings are presented in two sections, the first relating to video-linked lectures and the second relating to video-streaming.

\section{Video-linked lectures}

Participants demonstrated predominantly positive reactions towards the use of videoconferencing for teaching and learning. They valued the opportunity to be taught by experts drawn from a wide geographical area; for example:

I think it is important ... because we are spread out ... if the technology wasn't there we'd miss out on really interesting speakers that can't get across to our site.

They felt video-linked lectures complemented their other learning opportunities; for example:

... to have someone who is a professional and with that practical experience telling you the same thing it confirms and consolidates the knowledge that you've learnt in [other classes]. 
Responses suggested that participants preferred attending lectures at the live site where they could interact with the lecturer more easily; for example:

I think definitely being a live audience is much better ... you are just more involved and ... have the interaction of having a live speaker in front of you.

An additional factor was a shift in student behaviours at the remote site leading to distraction by their peers - for example:

... the thing that I find is a little bit annoying is that because there is no speaker in the room some people are far more relaxed and they will be chatting. There may be people chatting or you know people might get up and out so it's not quite as easy to watch as if there was someone in the room.

However, most participants reported making decisions about attendance based on whether the lecture topic seemed interesting - for example:

... very early on you decide what kind of aspects of medicine you like and what you don't like and what you think will be boring to sit through an hour lecture, where in your own time you could just read through a book or the slides on [the managed learning environment], so you'll decide just on what the subject topic is, whether you think it will be worth waking up at $9 \mathrm{am}$ to go to.

The other major factor affecting attendance was the speaker - for example:

Some of them [the speakers] are really good. If it is a lecture, say there is a lecturer that I know is really good, like I have seen her before, I am more likely to attend the lecture even though it is [video-linked].

When asked to summarise the characteristics of those speakers who come across well in video-linked lectures, the most frequently mentioned characteristic was an ability to interact with and engage audiences at both sites; for example:

there are the lecturers that involve both sites equally and they'll often do competitions between the two sites.

The most frequently cited technical issue related to microphone use and, particularly, the frustration associated with one of the audiences forgetting to use a microphone when asking questions - for example:

... say someone in [Site 1] asks a question, they won't use the microphone so you [in Site 2] won't hear what the question is, and if the lecturer doesn't repeat what the question was you'll have no clue of what's going on. It's annoying because you feel like you're not getting a full lecture.

The time delay in locating and accessing a microphone constituted a significant barrier to interactivity between sites.

\section{Use of video-streamed lectures}

Most participants said their attendance at real-time, video-linked lectures was not affected by the fact that they were recorded and made available in a video-streamed format later. Only a minority of participants used video-streamed lectures regularly 
and, even then, at a relatively low frequency, despite speaking very positively about their availability as a learning resource.

Approximately one-half of the participants expressed a preference for attending real-time lectures - for example:

I would still prefer to have the live lecture than the video streaming. I think it's just a case of, you get into a routine, get up, go to the medical school in the morning, whereas if you don't go to the live lecture you'll probably stay in bed another hour.

The most popular times to review streamed lectures were evenings, weekends and holidays.

Accessing video-streamed lectures appeared to serve three main purposes for participants. Firstly, to watch a streamed lecture they had missed and which was recommended by their peers; for example:

I have missed a lecture that everybody said was good ... if they [the peers] say it was brilliant then I watch it.

Secondly, to review lectures that were particularly informative - for example:

... if there was one that I thought 'that was a fantastic [lecture], I really enjoyed that', then I would go back to it. Not for enjoyment factor, not that I am saying I didn't enjoy it, but more because it was very informative and interesting.

Thirdly, to deepen their understanding of the material; for example:

If they [the speakers] were talking quickly and I didn't have chance to make all the notes, then I can go back.

Participants felt the main advantage of video-streaming was the ability to pause and rewind; for example:

... to be able to sit ... with the headphones on and watch a plenary was really good because you could stop it, and if you didn't quite understand something you could just rewind it and listen again.

\section{Discussion}

The use of digital technologies is increasing as a result of a desire to make most effective use of lecturer and students' time, and to avoid unnecessary travel and thereby carbon emissions. It is becoming increasingly difficult to justify not using these technological innovations, either economically or environmentally. However, it is vitally important that we evaluate the impact of digital technologies on student learning and ensure we use them to their best advantage, through a deep understanding of where they can enhance learning and where they might detract from it.

The current study employed a detailed qualitative methodology (semi-structured interviews) to explore medical students' perceptions of video-linked lectures and video-streaming, and how decisions are made about attending/accessing these. It complements the predominantly quantitative studies published to date, and provides an evidence base that is important to inform other medical educators interested in employing similar technologies in their teaching. 
The findings confirm that video-linked lectures and video-streaming are an acceptable alternative to face-to-face delivery and that students' primary concern tends to be teaching-related factors such as lecture content, speaker and delivery style rather than the technology employed. However, whilst there may be no significant difference in medical student attendance of live or remote lectures (Mattick, Crocker, and Bligh 2007), the current study shows that the remote site experience may be qualitatively less satisfying due to the diminished degree of engagement with the lecturer and the home audience. Elsewhere, both medical and physiotherapy students have felt interactivity to be compromised to some degree in video-linked lectures (Raffelini 2006; Mohammed, Waddington, and Donnan 2007) and medical student satisfaction was not quite as high for remote lecture attendance as for in-person attendance (Callas et al. 2004).

There is concern amongst some lecturers that the availability of video-streamed lectures might discourage students from attending the live event (Bell et al. 2001; Moridani 2007). The medical students in this study, however, reported that their attendance of live lectures was unaffected by the availability of a streamed version and other studies with medical students report similar findings (Dev et al. 2000; Billings-Gagliardi and Mazor 2007). However, it is possible that disciplinary differences may exist since, in another setting, computer science students did show diminished attendance at live events after the introduction of streamed lectures (Bell et al. 2001). Interestingly, students who no longer felt the need to attend live events were often dissatisfied with the limited interaction with lecturers that this entailed (Moridani 2007), which will be a concern for those settings where attendance is affected.

It is important for researchers to acknowledge the limitations of their work. Although this study made efforts to recruit both students who chose to attend lectures and those who chose not to attend, most of the interviewees belonged to the first group. This probably represents an unintended selection bias, with students that do attend lectures being more forthcoming in volunteering to participate in the study. This is an important observation and must be taken into account when interpreting the results. Future studies might employ different strategies to try to ensure representation of these important groups of students.

The findings presented in this study indicate that future research and development activity should focus on improving engagement and interactivity during video-linked lectures. We need to improve the quality, and equality, of communication and interaction between live and remote sites. This will require substantial investment in staff development for those individuals who deliver video-linked lectures; for example, in mastering a range of teaching strategies that can enhance interactivity between sites (Gill, Parker, and Richardson 2005). Investment in staff development could possibly be supplemented with further investment in technologies such as improved microphones and wireless audience response technology, although we consider this a secondary priority at the current time.

\section{Acknowledgements}

The authors would like to acknowledge the research participants, who gave freely of their time to be involved in the study. They would like to thank the Pathfinder project steering group and the project's critical friend, Betty Collis, for their input into the study design and the manuscript. Finally, the authors would like to thank the Higher Education Academy for funding, without which the research would not have been possible. 


\section{Notes}

1. See http://www.heacademy.ac.uk/ourwork/learning/elearning/pathfinder.

\section{References}

Bell, T., A. Cockburn, B. McKenzie, and J. Vargo. 2001. Digital lectures: If you make them, will students use them? Constraints on effective delivery of flexible learning systems. Interactive Multimedia Electronic Journal of Computer-Enhanced Learning 3, no. 2. http://imej.wfu.edu/articles/2001/2/06/index.asp.

Billings-Gagliardi, S., and K.M. Mazor. 2007. Student decisions about lecture attendance: Do electronic course materials matter? Academic Medicine 82, no. 10: S73-6.

Callas, P.W., T.F. Bertsch, M.P. Caputo, B.S. Flynn, S. Doheny-Farina, and M.A. Ricci. 2004. Medical student evaluations of lectures attended in person or from rural sites via interactive videoconferencing. Teaching and Learning in Medicine 16, no. 1: 46-50.

Carter, C., A. Clarke, R. Graham, and S. Pomfrett. 1996. The use of video conferencing in higher education. SIMA Report Series ISSN 1356-5370. http://www.agocg.ac.uk/reports/ mmedia/video6/title.htm.

Carville, S., and D.R. Mitchell. 2000. 'It's a bit like Star Trek': The effectiveness of video conferencing. Innovations in Education and Training International 37, no. 1: 42-9.

Dev, P., T.C. Rindfleisch, S.J. Kush, and J.R. Stringer. 2000. An analysis of technology usage for streaming digital video in support of a preclinical curriculum. Paper presented at the AMIA Symposium, November 4-8, in Los Angeles, USA. http://www.pubmedcentral.nih.gov/pagerender.fcgi?artid=2244014\&pageindex $=1$.

Freeman, M. 1998. Video conferencing: A solution to the multi-campus large classes problem? British Journal of Educational Technology 29, no. 3: 197-201.

Gill, D., C. Parker, and J. Richardson. 2005. Twelve tips for teaching using videoconferencing. Medical Teacher 27: 573-7.

Knipe, D., and M. Lee. 2002. The quality of teaching and learning via video conferencing. British Journal of Educational Technology 33, no. 3: 301-11.

Mattick, K., G. Crocker, and J. Bligh. 2007. Medical student attendance at non-compulsory lectures. Advances in Health Sciences Education 12: 201-10.

McCrohon, M., V. Lo, J. Dang, and C. Johnston. 2001. Video streaming of lectures via the Internet: An experience meeting at the crossroads. Paper presented at the 18th Annual Conference of the Australasian Society for Computers in Learning in Tertiary Education, December 9-12, in Melbourne, Australia. http://www.ascilite.org.au/conferences/ melbourne $01 /$ pdf/papers/mccrohonm.pdf.

Mohammed, Y.Q., G. Waddington, and P. Donnan. 2007. Face-to-face vs. real-time clinical education: No significant difference. The Electronic Journal of e-Learning 5, no. 4: 287-96.

Moridani, M. 2007. Asynchronous video streaming vs. synchronous videoconferencing for teaching a pharmacogenetic pharmacotherapy course. American Journal of Pharmaceutical Education 71, no. 1: article 16. http://www.ajpe.org/view.asp?art=aj710116\&pdf=yes.

Pitcher, N., K. Davidson, and J. Goldfinch. 2000. Video conferencing in higher education. Innovations in Education and Training International 37, no. 3: 199-209.

Raffelini, C. 2006. An evaluation of the training activities provided by videoconferencing in a university hospital centre. Innovations in Education and Teaching International 43, no. 3: 261-77.

Soloman, D.J., G.S. Ferenchick, H.S. Laird-Fick, and K. Kavanaugh. 2004 A randomised trial comparing digital and live lecture formats. BMC Medical Education 4: 27. http:// www.biomedcentral.com/1472-6920/4/27.

Stain, S.C., M. Mitchell, R. Belue, V. Mosley, S. Wherry, C.Z. Adams, K. Lomis, and P.C. Williams. 2005. Objective assessment of videoconferenced lectures in a surgical clerkship. The American Journal of Surgery 189: 81-4.

Whitten, P., D.J. Ford, N. Davis, R. Speicher, and B. Collins. 2005. Comparison of face-to-face versus interactive video continuing medical education delivery modalities. The Journal of Continuing Education in the Health Professions 18: 93-9. 


\section{Appendix 1. Semi-structured interview schedule}

\section{Question number}

\section{Section A: Particular experience of video-linked lectures}

1. Before attending any, what was your expectation of telematic lectures?

Prompt: were you generally positive about the prospect?

2. Now that you have experienced them, to what extent do you attend telematic lectures?

3. What is your general impression of telematic lectures?

Prompt: What is good about them? What is not good?

Prompt: What about from a technical / organisational / pedagogical / social / cultural point of view?

Prompt: To what extent have telematic lectures lived up to your expectations?

4. How do you go about deciding which telematic lectures to attend?

5. How do you compare the experience of attending telematic lectures in the live and the remote site?

6. To what extent do you think the use of telematic lectures suits the subject area (medicine)?

7. To what extent do you think the use of telematic lectures suits your learning preference?

8. What is the impact of telematic lectures on your overall study?

Prompt: How important are they to your overall study?

Prompt: How would you feel if this part of your timetable was removed?

9. Have you encountered any problems with telematic lectures?

Prompt: If so, what was their nature (e.g. technical / organisational / pedagogical / social / cultural)?

Prompt: Are these problems now solved or ongoing?

10. Did you receive any help or support for learning via telematic lectures, for example to help you get the most out of them?

11. Would any additional support have been helpful - and if so what?

12. What are the characteristics of those speakers who come across well in telematic lectures?

13. Do speakers appear to be generally well prepared for teaching via telematic lectures?

14. Do you think speakers require any additional support - and if so what?

\section{Section B: Particular use of video-streaming}

15. To what extent do you access video-streamed lectures?

Prompt: If never, why not?

16. What is your general impression of video-streamed lectures?

Prompt: What is good about having this as a resource? What is not good?

Prompt: Do you perceive there to be any technical / organisational / personal issues?

17. What is your main motivation for watching a streamed lecture?

Prompt: For example, instead of attending a telematic lecture, to deepen understanding of the topic, to see an inspiring lecturer, to revise for assessment etc) 


\section{Appendix 1. (Continued)}

\section{Question number}

Prompt: Are they high quality, recommended by peers, on a complicated topic, on a topic you are particularly interested in etc?

19. How important are streamed lectures to your study?

Prompt: How would you feel if this part of your timetable was removed?

20. Where do you usually access streamed lectures?

Prompt: at home? In the IT suites?

21. When do you access streamed lectures?

Prompt: at weekends? In holidays? What time of day?

22. How long after the telematic lecture do you usually access the streamed lecture?

23. Do you normally watch the whole streamed lecture or only part of it?

Prompt: If only part of it, would you like to explain which part you watch? E.g. the beginning / middle / end, the part you remembered?

Prompt: Can you estimate the average amount of time that you watch for?

24. Have you experienced any technical difficulties with the streamed lectures? If so, what was the impact of these?

Prompt: Impact on your learning, motivation etc.

25. What are the advantages of the streamed lectures?

26. Apart from watching steamed lectures, do you use other forms of virtual learning environment e.g. online discussion forum, online chat etc. to support your learning?

\section{Section C: The wider learning context}

27. What is the most exciting learning experience in your course?

Prompt: How does this differ from your experiences of telematic lectures?

28. Does the structure of this course suit your learning preferences?

29. For your learning preferences, what would be the perfect balance of telematic lectures to other timetabled sessions?

30. To what extent will you continue to attend telematic lectures or access streamed plenaries in the coming years? 